Acta Poetica $26(1-2)$

PRIMAVERA-OTOÑO

2005

\title{
Paremias étnicas en el refranero mexicano
}

\author{
Nieves Rodríguez Valle
}

En este artículo se analizan las paremias étnicas del refranero mexicano, es decir, aquellas paremias en las que se encuentra mencionado el estereotipo de un grupo étnico: el indio, el español, el gachupín, el criollo y el mestizo. Se analizan las características específicas de este tipo de paremias, las cuales comparten con el resto, por lo general, sólo la forma. Se observan sus antecedentes y su contenido, mismo que expresa los desencuentros y el racismo hacia los otros, así como el complejo entramado de la sociedad mexicana sintetizado en estas frases populares.

This paper deals with ethnic proverbs in the Mexican Refranero. These proverbs express racism against others within complex Mexican society such as: Indian, Spanish, Gachupin, Creole and Mestizo. This type of paremia has specific characteristics, analized by the author, who also observes its antecedents and contents. 
Acta Poetica 26 (1-2)

PRIMAVERA-OTOÑO

2005

Nieves Rodríguez Valle

Universidad Nacional Autónoma de México

\section{Paremias étnicas en el refranero mexicano}

\section{Generalidades}

Las paremias - los refranes, las frases proverbiales, las sentencias, los dichos, en fin todos lo enunciados sentenciososque vinieron con la lengua española a tierras americanas se arraigaron y, como la lengua misma, siguieron su propio camino. Muchas de ellas permanecieron idénticas; otras, se modificaron para adaptarse a la nueva realidad, ya sea por la sustitución de palabras al incorporar léxico de las distintas lenguas que se hablaban en América como

El que con coyotes anda a aullar se enseña;

ya sea a través de la sustitución de imágenes

A todo guajolotito le llega su Nochebuena.

Otras paremias que nacieron aquí, criollas y mestizas, utilizan elementos, labores u objetos propios, para censurar o describir conductas humanas. Todas estas paremias conforman el refranero mexicano y se usan en nuestro argumentar cotidiano sin importar su origen. 
En este trabajo estudio un grupo específico de paremias surgidas de la interacción entre indígenas y españoles desde el comienzo de la Colonia, en particular a aquellas que incluyen en su enunciación a uno o varios grupos étnicos específicos como el indio, el gachupín, el español, el criollo y el mestizo.

Los textos seleccionados provienen en su mayoría de Los refranes del hablar mexicano en el siglo xx (2002) de Herón Pérez, que es hasta ahora el refranero mexicano más completo, pues recoge y amplía las recopilaciones anteriores.

Al analizar las paremias que contienen por lo menos un grupo étnico se observa que, en términos generales, pueden dividirse en dos clases: aquellas en las que el grupo étnico no es el objeto principal de la paremia y aquellas en donde sí lo es. Estas últimas constituyen el número mayoritario y forman una categoría aparte con características propias: las paremias étnicas.

Entre las paremias que incorporan personajes del entramado étnico mexicano, que no caen dentro de la categoría de paremias étnicas, se encuentran aquellas cuyo alcance es universal, como las siguientes donde aparece la india: Indio sin india, cuerpo sin alma (Pérez 2004, 251), en donde se exalta su valor en la integración de la pareja: el indio es el cuerpo y la india el alma; y La india quiere al arriero, cuando es más lépero y feo (Pérez 2004, 248) que, al igual que otras paremias relacionadas con la mujer, consideran que a ésta le gusta el maltrato. Como se observa, más que presentar características particulares de la india, estas paremias representan un pensamiento misógino.

Otras paremias cuyo valor es universal o cuyo objetivo no es el grupo étnico en particular son, por ejemplo: No tiene la culpa el indio, sino el que lo hace compadre (Pérez 2004, 167). ${ }^{1}$ En esta paremia se sanciona la imprudencia y la falta

${ }^{1}$ Variante: No tiene la culpa el indio, sino quien lo hace compadre (Pérez 2004, 167n). 
de juicio de quien se queja de algún daño sufrido por haber confiado en alguien indigno de confianza e incluso proclive a malas acciones (Santamaría 2000, 616a). Indio, en este caso, se asocia a un estereotipo negativo. El hecho original del que seguramente deriva este dicho se ha trascendido para obtener una significación más amplia; tal es así, que sobre la base de esta paremia se ha creado otra: No tiene la culpa el pulque, sino el briago que lo bebe (Pérez 2004, 167), la cual expresa que no se debe culpar a nadie de los propios errores; en este caso, la culpable no es la bebida sino el borracho (Pérez 2004, 167).

Otro ejemplo, La pujanza del dinero, hace al indio barrigón (Pérez 2004, 378), se centra en la advertencia sobre las conductas negativas que puede provocar el dinero.

Finalmente, encontramos la superstición prehispánica de que el canto del tecolote es augurio de muerte, como en los siguientes ejemplos:

Si el tecolote canta, el indio muere,

o bien,

Cuando el tecolote canta el indio muere; no es cierto pero sucede (Pérez 2002, 126). ${ }^{2}$

2 Sahagún registra dos agüeros de los que puede derivar esta creencia, en ninguno menciona específicamente al tecolote, sino los nombres españoles búho y lechuza: "Del mal agüero que tomaban del canto del Búho, ave: También cuando oían cantar al búho estos naturales desta Nueva España tomaban mal agüero, ora estuviese sobre su casa, ora estuviese sobre algún árbol cerca. Oyendo luego aquella manera del canto del búho, luego se atemorizaban y pronosticaban que algún mal les había de venir, o de enfermedad o de muerte" (Sahagún 2000, V, IV, 446). "Del mal agüero que tomaban del chillido de la lechuza: Cuando alguno sobre su casa oía charrear a la lechuza, tomaba mal agüero. Luego sospechaba que alguno de su casa había de morir o enfermar, en especial si dos o tres veces venía a charrear allí sobre su casa. Tenía por averiguada que había de ser verdadera su sospecha. Y si por ventura en aquella casa donde venía a charrear la lechuza estaba algún enfermo, luego le pronosticaban la muerte. Decían que aquél era el mensajero del dios Mictlantecuhtli, que iba y venía al Infierno [...] que andaba llamar a los que le mandaban” (Sahagún 2000, $\mathrm{V}, \mathrm{v}, 447)$. 


\section{Paremias étnicas}

Dentro de la clasificación propuesta en este trabajo, las paremias étnicas tiene varios rasgos distintivos que enumeraré a continuación. En primer lugar, cuentan con un sujeto que representa a un grupo, un estereotipo, es decir, "una forma de generalización aplicable a la conducta, actitud y modo de ser de un determinado grupo social, sea este étnico, de clase, regional o nacional" (Solís 1971, 18). En tanto que las paremias no étnicas suelen utilizar un sujeto impersonal: "Quien...", "El que...", "Al que...", que les da el carácter de universales, o, al hacer uso de la metáfora, se refieren al comportamiento humano en general.

La segunda característica distintiva es que las paremias étnicas se expresan como una declaración no como una metáfora. Es decir, su significado no es aplicable a otras situaciones. Mientras que en el refrán y, por lo general, en las otras paremias existe un sentido figurado, interpretable dentro de un contexto en donde a un enunciado textual o literal se superpone otro que está fuera del texto mismo y al que se refiere translaticiamente, para expresar un concepto más amplio (García 1999, 220).

En tercer lugar, a diferencia de las paremias en general que no funcionan como elementos aislados, sino insertas dentro un discurso en el cual cobran sentido, las paremias étnicas no se pueden aplicar a cualquier situación pues su sentido es describir, aconsejar o advertir sobre las precauciones que se deben tomar ante el grupo al que aluden. La voz que enuncia se distingue a sí misma, por medio de la devaluación y la descalificación del sujeto (estereotipo) al que hace referencia. En estas paremias el estereotipo étnico no es siempre el sujeto aunque sí el objeto.

Las paremias de ataque a otro grupo étnico, social o religioso, tienen su antecedente en el refranero español, puesto por escrito en los siglos XVI y XVII, que registra el racismo ante los 
judíos, por ejemplo: Al judio y al puerco, no le metas en tu güerto (Correas 2000, 59-60); No te fíes de judio, ni de su hijo, ni de su vecino (Correas 2000, 568). ${ }^{3}$ También se presenta, aunque en menor medida, el musulmán, el moro, asociado generalmente a la riqueza. ${ }^{4}$

Notorio es que en México se adoptaron algunas paremias sobre el moro - figura presente en estas tierras gracias a las representaciones religiosas de las luchas entre moros y cristianos. Un ejemplo de lo anterior es Cómicos y abogados, lo mismo hacen de moros que de cristianos (Pérez 2002, 108). También conservamos al moro en paremias donde representa el peligro: No es lo mismo oír decir moros vienen que verlos venir (Pérez 2002, 279); Hay moros en la costa y gatos en la azotea [o] No hay moros en la costa (Pérez 2002, 212). Y adoptamos textualmente la paremia en la que el moro está asociado con la riqueza: Prometer el oro y el moro (Pérez 2002, 366n.). ${ }^{5}$

En el refranero español de Correas, si bien existen pugnas regionales, no hay autocrítica como nación; cuando registra: Español loco, rompe lo sano y pone lo roto, el autor comenta que "esto lo dicen en Italia porque los españoles acuchillan las cueras y pican los vestidos por gala" (Correas 2000, 349). Sin embargo, en el refranero mexicano ningún grupo étnico queda bien parado, a todos se les ataca.

Las paremias étnicas, como hemos visto, no son universales, sino que presentan una visión despectiva del otro claramente diferenciado del que las enuncia; no utilizan la metáfora, sino la descripción de los defectos — reales o imaginarios- que atribuyen al estereotipo objeto de crítica de la paremia. Sin embargo, su estructura les permite pertenecer a las paremias y,

\footnotetext{
${ }^{3}$ Para paremias sobre judíos, cf. Correas 2000, 59-60, 406, 550, 568; Horozco 1986, núms. 742, 931, 1353-1357, 1475, 2105, 2730.

4 Para paremias sobre moros, véase Correas 2000, 27, 529, 661; Horozco 1986, núms. 221, 222, 1071, 1154, 2023, 2419.

5 Variantes: Te ofrecen el oro y el moro (Pérez 2002, 366); Prometen el oro y el moro (Correas 2000, 661).
} 
por lo tanto, compartir la autoridad de éstas dado el valor que les otorga la experiencia de la comunidad lingüística que considera incuestionable su peso argumentativo. La estructura bimembre con ritmo y rima es similar a la de los refranes. Veamos algunos ejemplos: 1) dos hemistiquios octosílabos unidos entre sí por rima consonante: Si es indio, ya se murió; / si es español, ya corrió (Pérez 2002, 352); 2) dos octosílabos con rima interna: Al mestizo, el diablo lo hizo; / al indito, el Dios bendito (Pérez 2002, 77); 3) dos pares de octosílabos que riman en pareado: Si quieres cuidar tu raza / a la india con indio casa; / no te parezca mejor / casarla con español (Pérez 2002, 356). Pueden seguir también fórmulas predeterminadas como mal-remedio: A barbas de indio, navaja de criollo (Pérez 2002, 57). Es decir, la crítica racial ha podido sobrevivir en las paremias gracias a sus rasgos de oralidad, como los recursos mnemotécnicos.

A continuación se expondrá los refranes ligados a cada grupo étnico por separado.

\section{El indio}

Esta es la denominación que dieron los conquistadores a los pobladores autóctonos de América, ya que para los españoles había "Indias Orientales y Occidentales; de la mayor parte de ambas y de lo descubierto de ellas es señor la majestad del rey Filipo tercero" (Covarrubias, Tesoro, s.v. india). Y como consecuencia, bajo la denominación indio se generalizó, por lo menos en la conciencia popular que documenta el refranero mexicano, a los variados grupos étnicos prehispánicos que perdieron su distinción para formar un solo conglomerado: Quien vio un indio ya los vio todos (Altamirano 1997, proverbio 82). ${ }^{6}$

\footnotetext{
6 Variante: Quien vio un indio, un pueblo y un mono ya lo vio todo (Pérez 2004, 252).
} 
La discriminación hacia los pobladores nativos procede del siglo XVI. La palabra indio, a principios del siglo XX, funcionaba en el habla de la ciudad de México como un insulto, cargada del desprecio, racismo y hostilidad ancestrales (Pérez 2004, 249-250).

En el refranero mexicano quedan reminiscencias de este desprecio, por ejemplo, al indio se le equipara con el burro: Indios y burros, todos son unos (Pérez 2002, 218); Los inditos y los burritos, de chiquitos son bonitos (Pérez 2002, 248); El burro para el indio, la mula para el mulato y el caballo para el caballero (Pérez 2002, 155), con su variante: Caballo a caballero, para el mulato mula, y para el indio burro (Pérez 2002, 98). ${ }^{7}$ Existe en estos ejemplos una correspondencia entre dos escalas: una axiológica, que califica a la otra, que es social, en orden ascendente y descendente respectivamente. El enunciador parece ser el criollo o el mestizo que se tiene por caballero; para Herón Pérez, la pareja fundamental de esta paremia es indio-burro, y las relaciones mulato-mula y caballero-caballo parecen sólo producto de un juego de palabras (Pérez 2004, 82). Una paremia más relaciona al indio con el burro: Para un burro, un indio; para un indio, un fraile (Pérez 2002, 313), donde se expresan los grados de terquedad entre los tres aludidos: si el burro es terco, más lo es el indio, pero más aún lo es el fraile. Asimismo, el indio y el fraile son tema de la paremia Ni indio ni fraile, cierra la puerta que abre (Pérez 2002, 273); de esta paremia existe una variante en la que perro y ladrón sustituyen al indio: Perro, ladrón y fraile, no cierran la puerta que abren (Pérez 2002, 316).

En otro grupo se declara al indio, ateo o ladrón, según la variante, en: Indio con puro, ateo seguro (Pérez 2002, 217), Indio con puro, ladrón seguro (Pérez 2002, 217n). ${ }^{8} \mathrm{El}$ indio con puro

\footnotetext{
${ }^{7}$ Sólo hemos encontrado la figura del mulato en estas paremias.

${ }^{8}$ Otras variantes: Indio que fuma puro, ladrón seguro; Indio que chupa puro, que menos que ladrón seguro (Pérez 2002, 217n.).
} 
es sospechoso, pues en una sociedad estratificada y rígida no es bien visto aquel que se comporta de manera distinta a la esperada; como veremos más adelante, el refranero censura al que aspira a ocupar un lugar que la comunidad juzga que no le corresponde, y a quien asume comportamientos de otros grupos.

El desprecio por el indio es también manifiesto en la paremia: Indio, pájaro y conejo, en tu casa, ni aún de viejo (Pérez 2002, 218). ${ }^{9}$ Según explica Herón Pérez, en esta paremia se "pone en el mismo nivel a los tres personajes de los que se aconseja no tenerlos en casa ni de viejos. El objeto del refrán es obviamente el indio; el pájaro y el conejo están sólo por necesidad de la rima consonante que hay entre sus hemistiquios" (Pérez 2004, 251). El indio es desagradecido según las paremias: Indio, pájaro y conejo, no conocen gratitud (Pérez 2004, 251n.), variante de la anterior es Indio comido, indio ido (Pérez 2002, 217).

El indio tampoco es confiable si atendemos a la paremia: Indio que mucho te ofrece, indio que nada merece (Pérez 2002, 217), pues su oferta es interesada. De este modo, la paremia aconseja tomar precauciones y no creer en sus ofrecimientos. En el refranero también se sugiere no alabarlo, ni darle la razón pues: Alabar al indio es engrandecerlo (Pérez 2004, 249), y No hay que darle la razón al indio aunque la tenga (Pérez 2002, 286).

Una paremia puede ser polisémica al sugerir varias interpretaciones, como: No hay indio que haga tres tareas seguidas (Pérez 2002, 283), que puede significar "tanto la fragilidad y pereza ancestrales con que la cultura hispanizante asume al indio, como lo supersticioso que es el indio con respecto a realizar tres actos iguales seguidos" (Pérez 2004, 252).

\footnotetext{
9 Variantes: De indio, pájaro y conejo, ni el pellejo; Indio, pájaro y conejo, mudarle el pellejo (Pérez 2002, 218n.).
} 
La vida del indio no es importante, según la paremia: Mueran indios que hartos nacen (Altamirano 1997, 46). La economía basada en la explotación se consideraba legítima, y otorgada por el mismo Dios: El dinero Dios lo da, y los indios lo trabajan (Pérez 2004, 182). Sin embargo, en los primeros años de la Conquista, se alza una voz de advertencia ante la crueldad de los españoles y de la explotación desmedida, y se registra un refrán producto de la experiencia que se atestigua con hechos concretos. Así lo explica Fray Toribio de Benavente o Motolinía en el capítulo 10 del tratado segundo de la Historia de los indios de la Nueva España, que titula "De algunos españoles que han tratado mal a los indios, y del fin que ha habido...":

Hase visto por experiencia en muchos y muchas veces, los españoles que con estos indios han sido crueles, morir malas muertes y arrebatadas, tanto que se trae ya por refrán: el que con los indios es cruel, Dios lo será con él, y no quiero contar crueldades, aunque sé muchas, de ellas vistas y de ellas oídas; mas quiero decir algunos castigos que Dios ha dado a algunas personas que trataban mal a sus indios. (Motolinía 1979, 109).

Motolinía ejemplifica la veracidad de este refrán con tres ejemplos similares, transcribimos el primero de ellos:

Un español que era cruel con los indios, yendo por un camino con indios cargados, y allegando en medio del día por un monte, iba apaleando los indios que iban cargados, llamándolos perros y no cesando de apalearlos, y perros acá y perros acullá; a esta sazón sale un tigre y apaña al español, y llévale atravesado en la boca y métese en el monte, y cómesele; y así el cruel animal libró a los mansos indios de aquél que cruelmente los trataba. (Motolinía 1979, 109)

Para dar más peso a su narración, Motolinía termina sus ejemplos diciendo: "y yo estuve luego cerca del lugar a donde 
fue comido". Ya sea a medio día, ya a media noche, los hechos suceden en el camino, en el monte, y son tigres y leones los medios que Dios utiliza para castigar a los españoles crueles con los indios. El "refrán”, como le llama Motolinía, sintetiza esta experiencia, y su función es moralizante, una advertencia de castigo divino.

Hay otras paremias que representan la contraparte de la visión negativa, como la que se refiere al indio de excepción: Indio inteligente, arzobispo o presidente (Pérez 2002, 217); o al indio valiente y luchador: Machete caído, indio muerto (Pérez 2002: 251); No es indio el que no se venga (Pérez 2002, 278).

\section{El gachupín}

Gachupín $^{10}$ es el término que se emplea popularmente para designar al español que habita en México; históricamente, es el hombre nuevo en esta tierra, que es poco diestro en las cosas de ella. Aunque se puede aplicar a cualquier español, tiene una connotación despectiva e injuriosa, y ha llegado a tener la significación específica del español plebeyo, rústico o de baja ralea (Santamaría 2000, s.v.).

El gachupín es un cierto tipo de español que dejó una amplia huella en el refranero mexicano que recoge la tradición trazada por la sátira popular novohispana. La figura del gachupín que allí se pergeña y que refleja una conciencia popular, probablemente mestiza, vislumbra al gachupín como un español insolente, indeseable, haragán, frágil, cobarde y dinerero. (Pérez 2004, 212)

10 Existen varias teorías sobre el origen de esta palabra. Según Santamaría puede derivar de cacchopini de cac (cactli) calzado y chopini puntapié. El Padre Mier la deriva de catzopini de cactli zapato y tzopini cosa que espina o punza, significando entonces "hombre con espuelas"; o del portugués cachopinho muchachito, o cachopo niño (Santamaría 2000, 541ab). 
Así, la sabiduría popular lo distingue del español, como lo muestra la clara diferenciación que establecen las paremias: Del español al gachupín, hay un abismo sin fin (Pérez 2004, 199); o, Al español, puerta franca; al gachupín, pon la tranca (Pérez: 2004, 199); ${ }^{11}$ pues Gachupín que se destapa, hasta la tumba no para (Pérez 2002, 205).

En forma de consejo algunas paremias expresan las precauciones que se deben tomar con el gachupín: Ni cambies peso, ni partas queso, ni tengas cajero gachupín (Pérez 2002, 272); Ni mujer que hable latín, ni hombre que hable como gachupín (Pérez 2004, 319). Otra paremia se expresa en forma de deseo y/o plegaria: Dios nos libre de un rayo, o un gachupín a caballo (Pérez 2002, 148). ${ }^{12}$

Lo indeseable de este estereotipo se expresa también en la siguiente paremia que describe que los peones de las haciendas administradas por gachupines padecen toda clase de malos tratos y tiranías: Gachupín amo en hacienda, siempre es causa de contienda (Pérez 2004, 212). ${ }^{13}$

En el refranero mexicano algunos rasgos físicos distinguen a los estereotipos de los grupos étnicos, por lo que la siguiente paremia avisa que no hay que fiarse de falsificaciones: No te fies de indio barbón, ni de gachupín lampiño, de mujer que hable como hombre, ni de hombre que hable como niño (Pérez 2002, 299 n). ${ }^{14}$ El refranero hispano del siglo XVII tenía su equivalente en: No hay que fiar de judio romo, ni de hidalgo narigudo [o] narigodo [o] narilongo (Correas 2000, 575).

\footnotetext{
11 Variante: Al español, puerta franca; al gachupín, la tranca (Pérez 2004, 199n.)

12 Existen variantes de esta paremia, más tardías, en las que el gachupín se sustituye por el pendejo: Líbreme Dios de un rayo, de un burro en el mes de mayo y de un pendejo a caballo (Pérez 2004, 188).

13 Variante: Gachupín en hacienda, siempre contienda (Pérez 2004, 212n.).

14 Variantes: No te fies de hombre barbudo, ni de español lampiño, de mujer que hable como hombre, ni de hombre que hable como niño (Pérez 2002, 299).
} 


\section{El español}

La visión del español es variada en el refranero. Como hemos visto, se presenta como más decente que el gachupín, pero se advierte que el español hace trabajar sin descanso a sus subordinados aunque no provoca "contiendas": Con mayordomo español, trabajo de sol a sol (Pérez 2002, 119). Se vuelve proverbial su terquedad e incapacidad para ponerse de acuerdo sobre un tema en: Tres españoles, cuatro opiniones (Pérez 2002, 371).

En Español que deja España y que a México se viene, cuenta le tiene (Pérez 2002, 201) se refleja el rencor con que el refranero mexicano ve al español que viene a México y se enriquece. También en forma de sátira, y de probable origen novohispano, se hace burla de los españoles que emigraban por necesidad y al llegar a México asumían el aire de personajes importantes y ostentaban títulos de nobleza: Piojos que en España mueren, en México resucitan (Pérez 2004, 365-366).

Desde la otra orilla varias paremias aconsejan a los españoles que vayan a "hacer la América" como lo recoge Sbarbi: Gánalo en México y gástalo en Madrid. Tiempo atrás Correas había registrado: El que va a las Indias es loco, y el que no va es bobo [o al trocado] (Correas 2000, 296).

\section{El indio y el español}

Además de la comparación de rasgos físicos que hemos visto arriba, algunas paremias establecen una comparación entre estos dos estereotipos, en cuanto a rasgos de personalidad, por ejemplo, se expresa que el indio es más valiente pues lucha hasta la muerte, en tanto que el español huye de manera cobarde: Si es indio, ya se murió; si es español, ya corrió (Pérez 2002, 352). ${ }^{15}$

${ }^{15}$ Variante: Si es indio, ya se murió; si es español, ya huyó (Pérez 2002, 352n.). 
Otra comparación se refiere a la longevidad: Cuando el indio encanece, el español desaparece (Pérez 2002, 125n.). ${ }^{16}$

Un desencuentro más entre los grupos que conforman la sociedad mexicana, se expresa abiertamente en el consejo de "cuidar la raza" y evitar el mestizaje, como en la paremia: Si quieres cuidar tu raza, a la india con indio casa; no te parezca mejor casarla con español (Pérez 2002, 356), donde es patente que la mayoría de los mestizajes ocurren entre mujer indígena y hombre español. ${ }^{17}$

\section{El criollo}

Santamaría afirma que este sustantivo está confinado a la América española o francesa y a las Filipinas: "Por criollo o créole se entiende el descendiente de españoles o franceses, sin mezcla de otra raza, nacido en las tierras americanas donde dominaron esas naciones" (Santamaría 2000, s.v.). En otras partes de América "lo criollo" significa lo nacional; en México, no tiene este significado, aunque ya desde el siglo XVII novohispano se intentó diferenciar, sin lugar a dudas, lo criollo y lo mestizo novohispanos de lo español. Las pugnas entre el español nacido en España y el nacido en México se reflejan en la paremia: Gachupín con criollo, gavilán con pollo (Pérez 2002, 205).

El criollo aparece poco y aislado de otros grupos en el refranero mexicano; una paremia advierte el cuidado que hay que tener con el criollo culto, el de costumbres urbanas: Con criollo civilizado anda siempre con cuidado (Pérez 2004, 161).

16 Variantes: Cuando el indio encanece, el blanco no amanece (Pérez 2002, 125); Cuando el indio encanece, el español ni parece; ...el español no aparece; ...el ladino ya no aparece (Pérez 2002, 125 n.); y la variante probablemente más tardía y secundaria con respecto al texto comparativo principal: ... ya tiene más de siete dieces (Pérez 2002, 249), que asienta que "el indio encanece a los setenta años; ello daría al español una esperanza de vida inferior a esa edad" (Pérez 2002, 249)

${ }^{17}$ En sentido opuesto existe la paremia contra el matrimonio de mujeres me- 
El criollo comparte algunas paremias con el indio, como: A barbas de indio, navaja de criollo (Pérez 2002, 57), que expresa la superioridad del criollo y su poder sobre el indio. El criollo o "lo criollo" se presenta como la aspiración del indio que reniega de sus costumbres y recibe la sanción popular, esta sanción refleja el concepto de estratificación; esto es, nadie puede aspirar a moverse del lugar establecido por los cánones dominantes: Indio que quiere ser criollo, al hoyo (Pérez 2004, 250); Indio que va a la ciudad, vuelve criollo a su heredad (Pérez 2002, 217); 18 "volver criollo a su heredad" significa "haber asumido los aires presumidos y soberbios del criollo" (Pérez 2004, 250-251).

\section{El mestizo}

Santamaría afirma que el término mestizo se aplica a la persona nacida de padre y madre de razas diferentes, y con especialidad al hijo de hombre blanco e india, o de indio y mujer blanca (Santamaría 2000, s.v.). Santiago Ramírez señala que el mestizo en México, salvo rarísimas excepciones, se encontró constituido por uniones de varones españoles con mujeres indígenas.

La unión de estas mujeres con hombres españoles fue una transculturación hondamente dramática. La mujer se incorporaba brusca y violentamente a una cultura para la que no se encontraba formada; su unión la llevaba al cabo traicionando a su cultura original. Por tanto, el nacimiento de su hijo era la expresión de su alejamiento de su mundo, pero no la puerta abierta a otro distinto. $(1968,48)$

\footnotetext{
xicanas con extranjeros se manifiestan en No te cases con extranjero, pues busca criada o dinero (Pérez 2002, 299).

18 Variante: Indio que va a la ciudad, vuelve criolla su heredad (Pérez 2002, 217n).
} 
En proporción con otras etnias, son muy pocas las paremias donde aparece el mestizo. Hemos encontrado sólo dos casos. En ambos se muestra gran desprecio por el mestizo y se exalta la figura del indio: Al mestizo, el diablo lo hizo; al indito, el Dios bendito (Pérez 2002, 77); Mestizo educado, indio renegado (Pérez 2002, 263n). ${ }^{19}$

\section{El mexicano}

En cuanto al estereotipo del mexicano sólo aparece en pocas paremias, dos de ellas relativas a su origen indígena y español respectivamente: Los mexicanos descienden de los aztecas, los peruanos descienden de los incas, los uruguayos descienden de los barcos (Pérez 2002, 248); y Los españoles de hoy son los mexicanos del mañana (Pérez 2002, 200). ¿Qué queda?: Pretencioso, flojo y vano: mexicano (Pérez 2002, 322); Mexicano: culo aguado, chinguirito ${ }^{20}$ y pan tostado (Pérez 2002, 263). Aunque Herón Pérez aclara que por mexicano se entiende, en estas paremias, al habitante de la ciudad de México, juzgado probablemente por los habitantes de provincia que muestran los rencores contra el capitalino; en tanto que la primera paremia se concentra en los defectos, la segunda, una variante, se ocupa de los rasgos y costumbres del capitalino (Pérez 2004, 294-295).

Finalmente, encontramos al mexicano en una paremia jactanciosa: Cada gallo canta en su corral; pero el mexicano, que es bueno [o muy bueno], canta en el suyo y en el ajeno (Pérez 2002, 102).

El refranero mexicano incluye una serie de paremias étnicas que se caracterizan por utilizar la estructura tradicional de los "refranes" (medida, ritmo y rima) — rasgo que les permite perdurar por generaciones y ser reconocidas como verdades sobre

19 Variante: Mestizo educado, diablo colorado (Pérez 2002, 263).

${ }^{20}$ Chinguirito, aguardiente de caña (Santamaría 2000, s.v.). 
las cuales argumentar, validadas por el sonido de antigüedad, por la comunidad linguística - para expresar un juicio de tono racista. Son generalizaciones sobre un grupo específico, no censuran, enjuician o dan un parecer sobre el comportamiento humano, sino sobre un grupo específico.

La complejidad propia del encuentro de dos culturas, con sus rivalidades, odios e identificaciones quedó registrada en las pocas palabras de las paremias. La cultura popular sintetizó en ellas los desencuentros. Y como consecuencia de esta experiencia compleja emergieron las paremias étnicas, que se deslizan entre las demás expresiones encubiertas en la aparente sabiduría popular.

Estas paremias que surgieron, se mantuvieron y funcionaron como tales a lo largo de nuestra historia pueden actualmente haber caído en desuso; pues, como dice Herón Pérez, las paremias tienen una vida histórica, "lo son mientras una comunidad les reconozca la capacidad discursiva de ser verdades del hablar; cuando pierden esa función, pierden su carácter" (Pérez 2004, 13). No obstante es interesante observarlas, tanto por su forma como por su contenido que devela parte de nuestra intrincada historia a través de las manifestaciones populares.

Es probable que, con los años, el refranero mexicano se nutra de nuevas paremias étnicas que incluyan otros estereotipos, como el gringo y el chicano, que quizá ya circulen en la oralidad presente, pero que necesitarán que la comunidad lingüística las acepte y las transmita por algunas generaciones y que el tiempo las decante.

\section{REFERENCIAS}

Altamirano, Ignacio Manuel, 1997 [1972]. Proverbios mexicanos, pról., transcripción y notas Andrés Henestrosa, México, Porrúa, ed. facsimilar. 
Correas, Gonzalo, 2000. Vocabulario de refranes y frases proverbiales (1627), ed. Louis Combet, revisada por Robert Jammes y Maïte Mir-Andreu, Madrid, Castalia.

Covarrubias, Sebastián de, 1995 [1611]. Tesoro de la lengua castellana o española, ed. Felipe C. R. Maldonado, Madrid, Castalia.

García-Paje, Mario, 1993. "Texto paremiológico y discurso poético (el ejemplo de Gloria Fuentes)", Paremia 1, 45-54.

Horozco, Sebastián de, 1986. Teatro universal de proverbios, ed. José Luis Alonso Hernández, Salamanca, Universidad de Salamanca.

Motolinía, fray Toribio de Benavente, 1979. Historia de los indios de la Nueva España. Relación de los ritos antiguos, idolatrías y sacrificios de los indios de la Nueva España, y de la maravillosa conversión que Dios en ellos ha obrado, ed. Edmundo O'Gorman, México, Porrúa.

Pérez Martínez, Herón, 2002. Los refranes del hablar mexicano en el siglo XX, México, El Colegio de Michoacán / Conaculta.

-, 2004. Refranero mexicano, México, Academia Mexicana / Fondo de Cultura Económica.

RAmírez, Santiago, 1968. El mexicano, psicología de sus motivaciones, México, Pax.

SAHAGún, fray Bernardino de, 2000. Historia general de las cosas de Nueva España, 3 vols., ed. Alfredo López Austin y Josefina García Quintana, México, Conaculta.

Santamaría, Francisco J., 2000 [1959]. Diccionario de mejicanismos, México, Porrúa, $6^{\mathrm{a}}$ ed.

Solís Garza, Hernán, 1971. Los mexicanos del norte, México, Nuestro tiempo. 